\title{
Pelatihan Pembuatan dan Aplikasi Pestisida Nabati dari Ekstrak Daun Kersen (Muntingia calabura L.) pada Pembibitan Tanaman Hortikultura di Kota Pontianak
}

\author{
Setiawan*1, Ismail Astar ${ }^{2}$, Sherly Oktarianty ${ }^{3}$ \\ 1,2,3Prodi Agroteknologi, Fakultas Pertanian, Universitas Panca Bhakti, Indonesia \\ *e-mail: iwansetiawan@upb.ac.id ${ }^{1}{ }^{\text {Ismailastar@upb.ac.id }}{ }^{2}{ }_{2}$ sherly oktarianty@upb.ac.id $^{3}$
}

\begin{abstract}
Abstrak
Pembibitan tanaman hortikultura di Kota Pontianak dihadapkan pada serangan hama seperti kepik dan kutu wol yang muncul pada musim penghujan. Hama ini akan sangat berdampak buruk pada tanaman yang sedanag dikembangkan. Tempat-tempat pembibitan tanaman samapai saat ini masih menggunakan bahan kimia untuk melakukan pengendalian hama secara cepat dapat berakibat terhadap ekosistem setempat yang makin buruk. Keadaan ini memerlukan inovasi baru yaitu pestisida organik dalam mengatasi peningkatan serang hama. Penerapan teknologi pertanian khususnya dalam pemanfaatan ekstrak daun kersen (Muntingia calabura L.) untuk mengendalikan hama kutu wol dapat meminimalisir kendala tersebut. Oleh karena itu perlunya melakukan penyuluhan dan pelatihan terhadap mitra kegiatan dalam usaha pembibitana tanaman hortikultura khususnya buah-buhan lokal secara berkelanjutan. Kegiatan pengabdian ini dikuti oleh beberapa pengusaha pembibitan yang ada di Kota Pontianak. Pelatihan pembuatan pestisida nabati dari daun kersen dapat meningkatkan pengetahuan dan pemahaman mitra dalam penggunaan pestisida nabati dalam membasmi hama kutu woL. Peningkatan pemahaman bagi peserta dilakukan dengan metode ceramah dan demonstrasi pembuatan dan aplikasi pestisida nabati dari daun kersen. Pemanfaatan ekstrak daun kersen dapat dijadikan sebagai pestisida nabati untuk penanggulangan hama kutu wol pada pembibitan tanaman yang dikembangkan oleh mitra dan mengurangi pengeluaran dalam pengendalian hama.
\end{abstract}

Kata kunci: Daun Kersen, Kutu Wol, Pestisida Nabati

\begin{abstract}
The nursery of horticultural plants in pontianak city is faced with the onslaught of pests such as ladybugs and wool lice that appear in the rainy season. These pests will greatly adversely affect the plants that sedanag developed. Local plant nurseries are still using chemicals to carry out rapid pest control that can result in poorer local ecosystems. This situation requires new innovations, namely organic pesticides in overcoming the increase in pest attacks. The application of agricultural technology, especially in the use of kersen leaf extract (Muntingia calabura L.) to control wool lice pests can minimize these constraints. Therefore, it is necessary to conduct counseling and training to activity partners in the efforts of breeding horticultural plants, especially local fruits in a sustainable manner. This devotional activity is curated by several nursery entrepreneurs in pontianak city. Training in making vegetable pesticides from kersen leaves can increase the knowledge and understanding of partners in the use of vegetable pesticides in eradicating wool lice pests. Increased understanding for participants was carried out by lecture methods and demonstrations of the manufacture and application of vegetable pesticides from kersen leaves. Utilization of kersen leaf extract can be used as a vegetable pesticide for the handling of wool lice pests in plant nurseries developed by partners and reduce expenditure in pest controL.
\end{abstract}

Keywords: Kersen Leaves, Vegetable Pesticides, Wool Lice

\section{PENDAHULUAN}

Hama kutu wol telah diketahui secara luas sebagai hama pada tanaman hortikultura baik dari bibit sampai tanaman yang telah besar di Indonesia sehingga menyebabkan kerugian ekonomi yang besar. Hal ini yang menyebabkan para penagkar atau pembibitan tanaman hortikultura mengalami kerepotan dalam mengendalikan serangan hama tersebut, untuk membantu kekurangan dalam perawatan pembibitan tanaman hortikultura yang ada di kota Pontianak perlu adanya kegiatan yang dapat meringankan para penangkar dengan kegiatan pengabdian kepada masyarakat yaitu dengan menggunakan daun kersen (Muntingia calabura 
L.) sebagai alternatif untuk pengendaliannya. Daun kersen (Muntingia calabura L.) telah diteliti mengandung beberapa senyawa yang berpotensi untuk mengendalikan serangan kutu wol. Daun kersen (Muntingia calabura L.) seperti bagian daun, buah, dan batang yang telah banyak dimanfaatkan oleh masyarakat untuk pengobatan alami (Suharto, 2007). Khusus bagian daun kersen memiliki kandungan tanin, flavonoid, saponin, serta senyawa polifenol yang dipercaya memiliki kemampuan sebagai antibakteri, antioksidan, dan antiinflamasi (Isnarianti et al., 2013). Berdasarkan uraian di atas maka penulis tertarik untuk melakukan pengabdian kepada masyarakat tentang pemanfaatan ekstrak daun kersen (Muntingia calabura L.) untuk mengendalikan hama kutu wol. Pengabdian kepada masyarakat ini bertujuan untuk mengetahui pengaruh ekstrak etanol daun kersen terhadap kutu wol, yang menyerang berbagai bibit buahbuahan sebagai inangnya. Ekstrak etanol daun kersen dengan konsentrasi yang berbeda yaitu 0\%, 2,5\%, 5\% dan 7,5\% disemprotkan ke permukaan dan bagian bawah daun bibit buah jambu biji (Psidium guajava), bibit durian dan bibit lainnya, dan diamati pengaruhnya terhadap kutu wol tersebut. Parameter dalam PKM ini yaitu jumlah pupa dan jumlah kutu wol dewasa. Data dianalisis menggunakan uji analisis varians (uji F) $\alpha=0,05$ dilanjutkan dengan uji Beda Nyata Terkecil (BNT) (Nasution, 2015). Hasil penelitian menunjukkan semakin tinggi konsentrasi ekstrak yang diuji maka semakin kuat pengaruhnya pada penurunan jumlah pupa dan kutu wol dewasa. Berdasarkan hasil penelitian ini maka ekstrak etanol daun kersen diharapkan dapat menjadi alternatif untuk pestisida sintetis (Indriati \& Khaerati, 2008).

Penerapan teknologi pertanian khususnya dalam pemanfaatan ekstrak daun kersen (Muntingia calabura L.) untuk mengendalikan hama kutu wol dapat meminimalisir kendala tersebut. Oleh karena itu perlunya melakukan penyuluhan dan pelatihan terhadap mitra kegiatan dalam usaha pembibitana tanaman hortikultura khususnya buah-buhan secara berkelanjutan (Agrios, 1996).

Mitra kegiatan dalam pengabdian kepada masyarakat ini adalah pembibitan Rizky Alam Borneo yang merupakan pembibitan tanaman buah-buahan dan berlokasi di jalan Tabrani Ahmad Jalan Bukit Batu Gg. Asmaja Pal 5 Kecamatan Pontianak Kota, Kota Pontianak, Kalimantan Barat. Pembibitan tanaman CV. Rizky Alam Borneo (RAB) bergerak dibidang pembibitan tanaman hortikultura yang menyiapkan bibit buah buahan unggul untuk disalurkan di wilayah kalbar dan sekitarnya. CV. RAB terletak di Jl. Husein Hamzah Gg. Asmaja Kecamatan Pontianak Kota, Kota Pontianak. Lokasi mitra berjarak $\pm 7 \mathrm{~km}$ dari Universitas Panca Bhakti, sehingga menjadi prioritas dari tim PKM untuk memberikan penyuluhan dan transfer ilmu mengenai penanganan hama terutama kutu wol.

Adapun jenis jenis bibit yang diusahakan oleh CV. RAB meliputi : Durian asal Kalimantan Barat yang telah dirilis dan ditetapkan sebagai durian unggul nasional seperti D. Kalapet asal Kayu Tanam Mandor, D. Aspar asal desa Mabah, Kenaman, Balai Karangan, D. Raja Mabah asal desa Mabah, Kenaman, Balai Karangan, D. Sawah Mas asal desa Mabah, Kenaman, Balai Karangan, D. Lay mansau asal Kota Sintang, D. Bahar asal Balai Karangan, D. Lokad, Manjar, Rinbud, Serumbut, Torong, Belening, Jemungko Kuning, Slipi, dan durian Tembaga, D. Kunyit, dan lain-lain. Selain bibit durian, CV. RAB juga membudidayakan bibit tanaman yang lain seperti rambutan, lengkeng, sawo, nangka, cempedak, nangkada, jeruk manis, jeruk purut, jeruk sambal, alpukat, pisang, jambu air, jambu batu, belimbing, langsat, kecapi, kedondong, mangga, manggis, buah naga, sirsak, dan lain lain.

Kendala-kendala/permasalahan yang dihadapi pembibitan ini adalah pada saat musim hujan biasa terjadi serangan hama seperti kepik dan kutu wool. Dengan adanya masalah serangan hama seperti ini pembibitan ini belum bisa atau mampu untuk mengatasi serangan hama seperti itu, untuk itu diperlukan bantuan dari pihak luar yang bisa mengatasi serangan hama tersebut. Diasumsikan dengan adanya bantuan dari pihak luar untuk mengendalikan serangan hama tersebut pihak pembibitan ini akan terbantu dan meringankan dalam berusaha. Di pembibitan ini belum adanya upaya atau uasaha dari pemilik pembibitan ini untuk mengatasi serangan hama tersebut, jadi hanya pasrah begitu adanya padahal pembibitan ini diharapkan sekali keberadaannya untuk menunjang pelestarian kekayaan alam kalbar dengan plasma nutfahnya. 


\section{METODE}

Kegiatan Pengabdian Kepada Masyarakat dalam skema Program Kemitraan Masyarakat (PKM) ini bertujuan sebagai alternatif untuk mengurangi ketergantungan terhadap insektisida sintesis dengan memanfaatkan daun kersen sebagai insektisida alternatif dan dapat menekan biaya pengolahan pembibitan tanaman yang dikembangkan oleh mitra sehingga dapat mendukung sistem pertanian berkelanjutan (sustainable farming).

Metode yang digunakan dalam skema Program Kemitraan Masyarakat (PKM) ini yaitu metode penyuluhan. Metode ini melibatkan penyuluhan tentang substansi kegiatan pembuatan insektisida nabati dari daun kersen disertai dengan demonstrasi dalam realisasinya.

Untuk mencapai target yang diharapkan, kegiatan ini dilakukan dengan beberapa tahap yaitu tahap persiapan, tahap pelatihan dan pelaksanaan, serta tahap evaluasi.

1. Tahap Persiapan

Tahap persiapan dilakukan dengan observasi lokasi dan koordinasi dengan pimpinan CV. RAB yang menjadi mitra pada kegiatan ini untuk membahas kegiatan penyuluhan berdasarkan masukan dan keinginan mitra. Penyuluhan dilakukan berupa pelatihan pembuatan insektisida nabati dari daun kersen untuk mengatasi hama kutu wol.

2. Tahap Pelatihan dan Pelaksanaan

Tahap pelatihan dan pelaksanaan yang dilakukan oleh tim PKM adalah sebagai berikut:

a. Sosialisasi dan penyuluhan kepada mitra. Kegiatan ini bertujuan merubah prilaku dan kebiasaan mitra dalam budidaya tanaman hortikultura.

b. Melakukan kegiatan pretest dan post test terhadap mitra agar memperoleh informasi kemampuan mitra serta bahan evaluasi kegiatan PKM ini.

c. Demonstrasi pembuatan insektisida nabati dari daun kersen sebagai pembasmi hama kutu wol.

3. Tahap Evaluasi

Evaluasi dilaksanakan agar tim PKM bersama mitra dapat mengetahui kendala-kendala apa saja selama kegiatan ini serta solusi apa saja yang dapat dilakukan. Monitoring dan pelaksanaan kegiatan dilakukan melalui tanya jawab, diskusi dan menyebarkan kuesioner sebelum dan sesudah pelaksanaan kegiatan kepada mitra.

Adapun prosedur kerja untuk mendukung metode pendekatan yang akan dilaksanakan dalam pembuatan bahan pestisida nabati dari daun kersen adalah sebagai berikut.

1. Bahan-bahan

a. $1 \mathrm{~kg}$ daun kersen.

b. Batang dan buah kersen secukupnya (kurang lebih 1 genggam).

c. Air kurang lebih 4 liter.

d. $1 / 4$ batang sabun

2. Cara Pembuatan

a. Masak $1 \mathrm{~kg}$ daun kersen ke dalam 2 liter air selama 30 menit.

b. Tambahkan lagi segenggam daun, batang, dan buah kersen.

c. Tambahkan lagi 2 liter air.

d. Aduk hingga merata.

e. Biarkan selama 6 jam.

f. Saring dan tambahkan $1 / 4$ batang sabun.

3. Aplikasi

Semprotkan selama 2 hari sekali jika jumlah kutu yang menyerang tanaman cukup banyak. Perlu diwaspadai, bahwa daun kersen merupakan insektisida yang cukup berbahaya bagi manusia. Karena kandungan zat-zat kimia beracun pada daun kersen menjadi lebih aktif lagi setelah dimasak. Oleh karena itu, gunakan sarung tangan dan masker penutup mulut saat menyemprotkan cairan tersebut. 


\section{HASIL DAN PEMBAHASAN}

\subsection{Sosialisasi dan Demonstrasi}

Sosialisasi dan simulasi ini merupakan rangkain dari beberapa kegiatan pembuatan pestisida nabati dari daun kersen, untuk pembuatan pestisida nabati Gambar 4. Sosialisasi dan Simulasi Pemanfaatan Daun kersen Sebagai Pestisida nabati diberikan kepada pembibitandi Kota Pontianak. Kegiatan sosialisasi berupa pemahaman tentang cara membuat pestisida nabati dengan bahan baku berupa daun kersen. Kegiatan sosialisasi ini dilakukan agar masyarakat terutama pembibitan tanaman di Kota Pontianak paham dan mengerti bagaimana cara memanfaatkan daun kersen yang baik dan benar sehingga bisa membantu petani untuk meningkatkan produktivitas pertanian dengan menggunakan pestisida tanpa bahan kimia berbahaya.

Kegiatan sosialisasi pemanfaatan daun kersen sebagai pestisida nabati juga didampingi oleh tim BPP Kota Pontianak sebagai bentuk dukungan dari pemerintah dalam kegiatan sosialisasi tersebut. Hal ini tentunya akan mempermudah dalam pengaplikasian oleh masyarakat tentang pemanfaatan daun kersen sebagai pestisida nabati. Harapannya setelah dilakukan sosialisasi dan pemaparan tentang pemanfaatan limbah tersebut, dari pihak pemerintah terutama dari tim BPP dapat terus mendampingi dan meberikan arahan kepada kelompok pembibitan tanaman dalam pemanfaatan daun kersen menjadi pestisida nabati. Gambar 1 menunjukkan serangan kutu wol terhadap tanaman hortikultura yang dikembangkan oleh mitra kami.
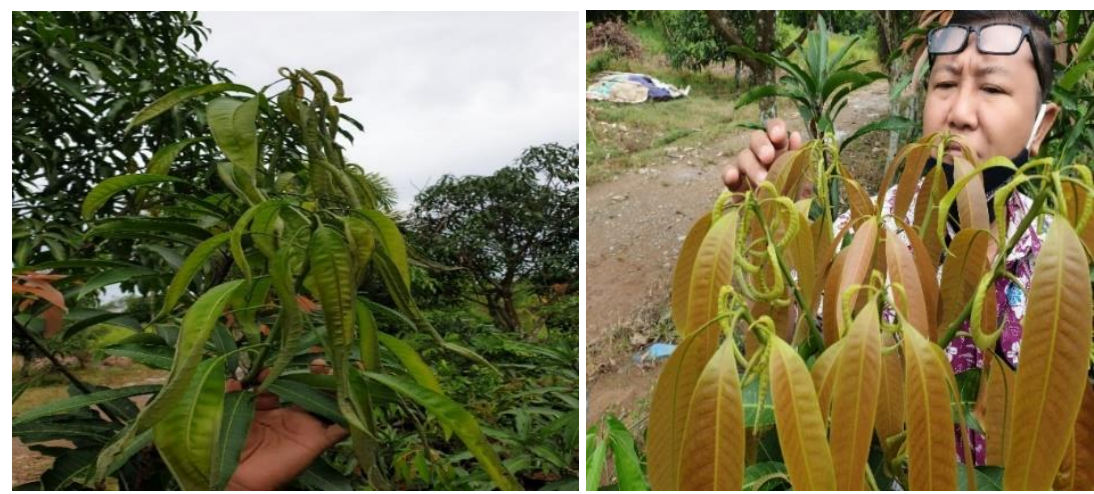

Gambar 1. Daun manga yang terkena hama kutu wol

Selain pemaparan sosialisasi juga dilakukan kegiatan demonstrasi pembuatan pestisida nabati dari limbah pertania. Demonstarsi pembuatan pestisida nabati dari daun kersen dilaksanakan di lokasi pembibitan tanaman Rizky Alam Borneo Pontianak. Bahan yang digunakan dalam pembuatan pestisida nabati adalah daun dan dahan pohon kersen. Secara umum, pestisida nabati yang dibuat merupakan pestisida namabti alami. Proses pembuatan pestisida nabati dilakukan di tempat terbuka dengan sirkulasi udara yang baik. Proses demonstrasi pembuatan pestisida nabati dari daun kersen dapat dilihat pada Gambar 2.
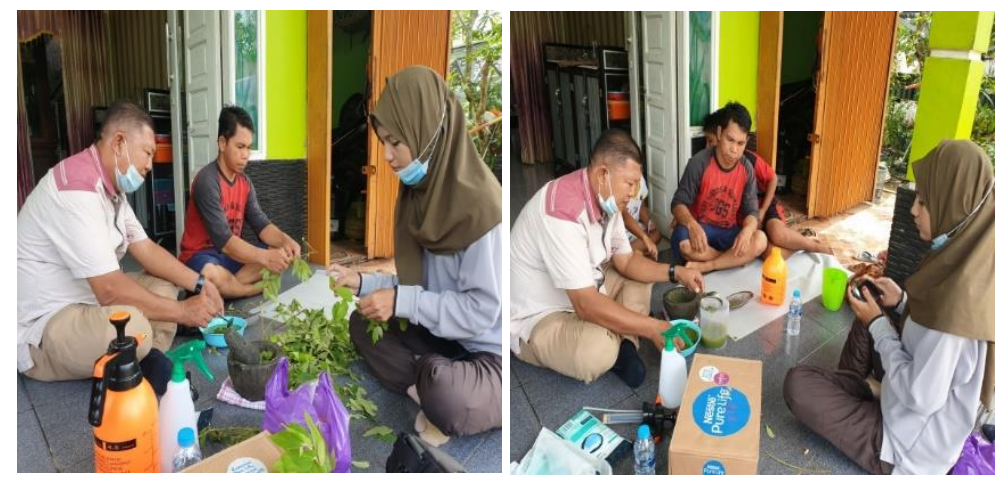


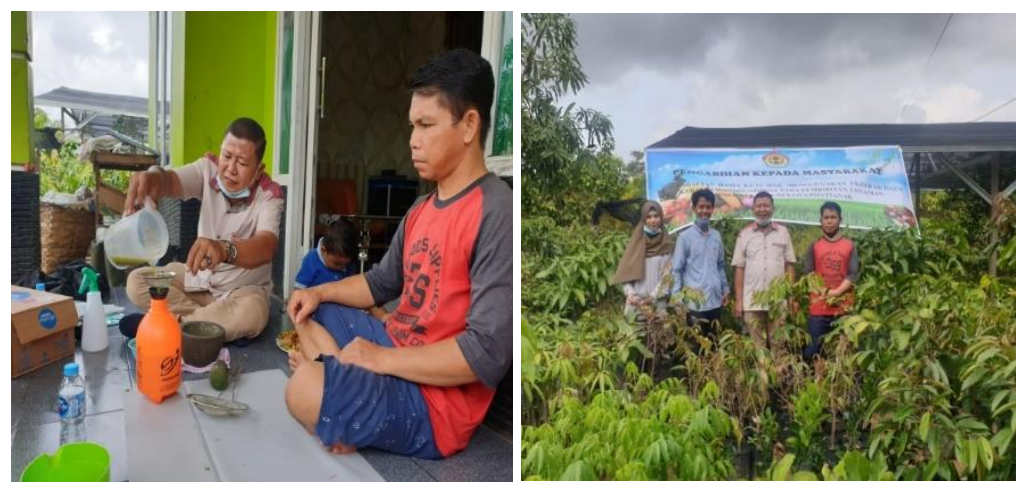

Gambar 2. Demonstrasi pembuatan pestisida nabati dari daun kersen.

Pembuatan pestisida nabati dari daun kersen dilakukan dengan tahapan sebagai berikut:

a. Masak $1 \mathrm{~kg}$ daun kersen ke dalam 2 liter air selama 30 menit.

b. Tambahkan lagi segenggam daun, batang, dan buah kersen.

c. Tambahkan lagi 2 liter air.

d. Aduk hingga merata.

e. Biarkan selama 6 jam.

f. Saring dan tambahkan $1 / 4$ batang sabun.

\subsection{Aplikasi pestisida nabati}

Pengaplikasian pestisida nabati dilakukan setelah ekstrak daun kersen didapatkan. Ekstran daun kersen yang sudah disaring dan diencerkan dengan air kemudian disemprotkan selama 2 hari sekali jika jumlah kutu yang menyerang tanaman cukup banyak. Perlu diwaspadai, bahwa daun kersen merupakan insektisida yang cukup berbahaya bagi manusia. Karena kandungan zat-zat kimia beracun pada daun kersen menjadi lebih aktif lagi setelah dimasak. Oleh karena itu, gunakan sarung tangan dan masker penutup mulut saat menyemprotkan cairan tersebut.

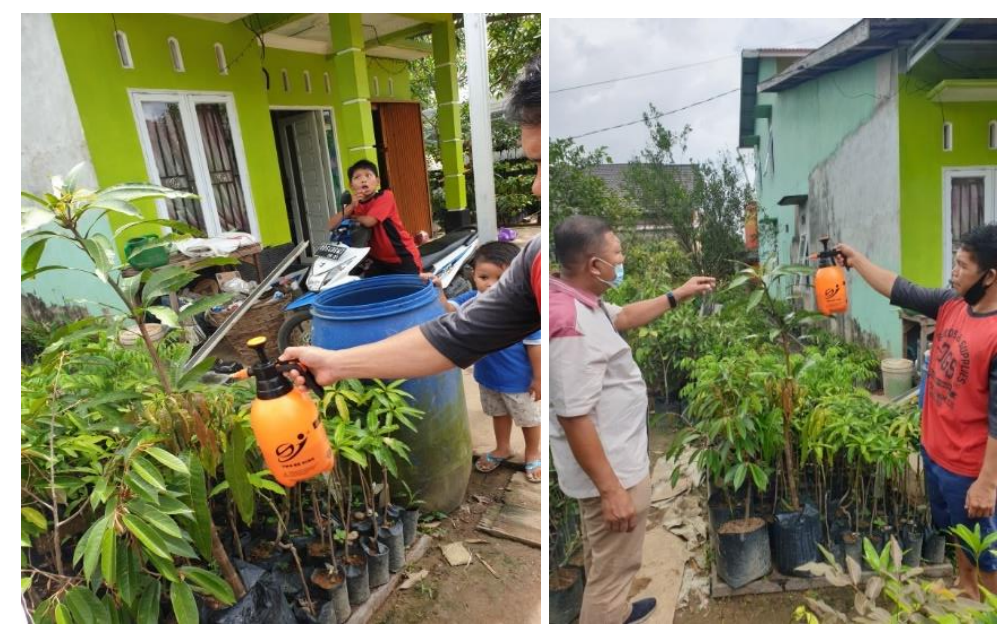

Gambar 3. Aplikasi pestisida nabati daun kersen pada bibit tanaman

\subsection{Evaluasi Kegiatan}

Setelah pelaksanaan demonstrasi pembuatan pestisida nabati selesai, maka dilakukan evaluasi pada akhir kegiatan. Evaluasi dilakukan berupa diskusi dan tanya-jawab antara pemateri dan masyarakat yang mengikuti kegiatan sosialisasi tersebut. Dari hasil diskusi dan tanya jawab tersebut dapat dilihat melalui kemampuan peserta dalam menyerap materi yang diberikan. Seperti misalnya pemateri bertanya tentang pengalaman menggunakan pestisida yang berbahan kimia dengan hasil kurang memuaskan. Hasil diskusi dan tanyajawab para peserta telah mampu memahami cara membuat pestisida nabati dengan memanfaatkan daun 
kersensebagai bahan dasarnya. Peserta sosialisasi khususnya para petani bibit buah-buahan yang ada di Kota Pontianak khususnya Rizki Alam Borneo mulai mengerti dan sadar bahwa banyaknya daun kersen yang terdapat di Kota Pontianak harus dimanfaatkan dengan baik.

Dalam setiap pelaksanaan suatu program tentu tidak selamanya sesuai dengan perencanaan yang dilakukan sebelumnya. Adapun hambatan yang didapatkan selama pelaksanaan pengabdian kepada masyarakat di Kota Pontianak faktor cuaca yang tidak menentu sehingga pelaksanaan sosialisasi dan aplikasi pestisida nabati dari daun kersen sedikit terhambat. Di lain pihak, masalah kurangnya dana yang digunakan dalam kegiatan selalu menjadi hal yang paling urgen.

\section{KESIMPULAN}

Kegiatan pengabdian kepada masyarakat ini diperoleh kesimpulan bahwa pemanfaatan ekstrak daun kersen dapat dijadikan sebagai pestisida nabati untuk penanggulangan hama kutu wol pada pembibitan tanaman yang dikembangkan oleh CV Rizki Alam Borneo. Pelatihan pembuatan pestisida nabati dari daun kersen dapat meningkatkan pengetahuan dan pemahaman mitra dalam penggunaan pestisida nabati dalam membasmi hama kutu wol. Peningkatan pemahaman bagi peserta dilakukan dengan metode ceramah dan demonstrasi pembuatan dan aplikasi pestisida nabati dari daun kersen.

\section{UCAPAN TERIMA KASIH}

Penulis mengucapkan terima kasih kepada Rektor Universitas Panca Bhakti yang telah memberi dukungan financial terhadap pengabdian ini.

\section{DAFTAR PUSTAKA}

Agrios, G., 1996, Ilmu Penyakit Tumbuhan. Gajah Mada University Press: Yogyakarta.

Indriati, G dan Khaerati 2008, Pengendalian serangga vektor Ferrisia virgata pada tanaman lada dengan pestisida nabati, Buletin RISTRI 1 (2): 101-104.

Isnarianti, R., Ivan A. Wahyudi, Rini M. Puspita, 2013, Muntingia calabura L Leaves Extract Inhibits Glucosyltransferase Activity of Streptococcus mutans, Journal of Dentistry Indonesia 2013, VoL. 20, No. 3, 59-63.

Nasution, B, Arifin.,2015, Keanekaragaman Spesies Kutu Putih (Hemiptera: pseudococcidae) pada tanaman buah-buahan di bogor. Skripsi Institut Pertanian Bogor. Bogor.

Suharto, 2007, Pengenalan dan Pengendalian Hama Tanaman Pangan, Andi offset. Yogyakarta. 